\title{
RECURRENCIAS TEMÁTICAS EN LA NOVELA HISPANOAMERICANA (I)
}

\author{
Jovita BOBES NAVES \\ Universidad de Oviedo
}

\section{Panorama}

La novela hispanoamericana trata recurrentemente un tema: el poder. Sus variantes textuales se pueden agrupar por los rasgos destacados en cada ocasión.

a) El poder se encarna en un personaje, el dictador, que lo ejerce despóticamente y da origen a las "novelas de dictador" que desde el siglo pasado llegan hasta hoy. Muchos de sus rasgos repetidos se han convertido en verdaderos signos del género y se encuentran en casi todos los relatos de este tipo.

b) En las novelas indigenistas, un pueblo o raza ha sido y es sojuzgado por el blanco o el criollo. Los conflictos que presentan son los de un grupo social frente a otro que se aprovecha de las ventajas de leyes realizadas a espaldas de los indios y sin contar con sus costumbres y tradiciones.

Como variantes están las novelas en que indios y criollos son explotados por los yankees, en haciendas agrícolas, mineras e industriales realizadas de forma primitiva por los indios, y científica y racionalmente por los foráneos.

c) Las novelas de espíritu revolucionario, en las que la situación de estudiantes, indios, civiles, pueblo en general, es tan desesperada que se revuelven contra los tiranos o los explotadores. Los más preparados culturalmente de los marginados, con ideas revolucionarias, casi siempre de origen marxista, hacen suya la tarea de aprovechar el descontento de todos y actúan contra los que detentan el poder: gobiernos, grupos yankees, grupos sociales que conservan el poder feudal, etc.

Caso especial es el de algunas novelas mejicanas actuales, aparte las llamadas de revolución, al tratar el problema del partido único y la designación 
de candidato presidencial que actuará de tirano mientras dure su mandato. La oligarquía, recién estrenada de la industria, condiciona la vida y la política de un pueblo. Se llega a la imposición de un dictador por otro que en apariencia se ocupa de actividades comerciales e industriales.

Esquematizados los diferentes tipos novelísticos tenemos:
A) Novelas de dictador
B) Novelas indigenistas y de explotación de extranjeros sobre los autóctonos.
C) Novelas de espíritu revolucionario.

Los recursos repetidos pueden formalizarse de tal modo que se convierten en verdaderos signos literarios cuyo significado es siempre el mismo: el dominio del hombre por el hombre.

Las variaciones son múltiples, pero se mantiene en cada creación un número de rasgos diferenciadores que producen una suerte de intertextualidad (Angenot, 1983) que afecta a la construcción misma de la novela. Se crea un horizonte de expectativas que permite al escritor la condensación de enunciados sugeridos más que realmente materializados en cada obra.

En estas novelas el poder sería el contenido significativo o idea común que se manifiesta a través de diferentes formas.

\section{Elementos Comunes}

Las novelas del poder presentan elementos comunes desde el punto de vista de su tratamiento en el discurso: entre ellos destaca el espacio. El marco para todos los relatos es el de las tierras americanas o macroespacio genérico; pero de él se desglosan espacios más reducidos y concretos en cada clase de relato: son los micro-espacios ambientales, significativos para el desarrollo de la anécdota concreta.

En las novelas del dictador la ambientación preferente es urbana, sobre todo una vez conseguido el poder; el campo o pequeños núcleos de población rural aparecen en las novelas que tienen por protagonistas a los indios o criollos. Urbanas o rurales son las ambientaciones de las novelas revolucionarias, incluso recorren países enteros para propagar ideas, como en Mascaró, el cazador americano de $\mathrm{H}$. Conti, y en ocasiones países distintos al de procedencia del autor, en Hispanoamérica o en Europa, como en Días y noches de amor y de guerra de E. Galeano, o en el Libro de Manuel de J. Cortázar.

Otro elemento común es la presentación del pueblo dividido en dos clases, los tiranos y los tiranizados, protagonistas individuales o colectivos, pero 
siempre como seres que ejercen o sufren el poder.

El tiempo es otro de los elementos comunes significativamente tratado. Las innovaciones técnicas en el uso de este elemento son especialmente privilegiadas en algunos relatos.

En muchas novelas un gran abigarramiento de materiales proporciona un barroquismo que se ve favorecido por el recurso de la intertextualidad, utilizado como elemento básico para la creación novelesca. Su valor significativo es notable. Todos los autores se sirven del procedimiento como si la novela fuese "algo que deviene, como un proceso", cuyo estudio debe plantearse como el de "un diálogo de múltiples textos, como un diálogo textual, o, mejor dicho, como una intertextualidad" (Kristeva, 1974, pág. 22).

Las distintas clases de novelas siguen hoy fieles a los elementos fundamentales que las caracterizan, pero su formalización es tan notable que hay tendencia a unificar y mezclar los distintos signos en una versión integradora que resulta un compendio de experiencias, vividas por un solo individuo como podemos ver en la obra de I. Allende, Eva Luna. A través de ellas se alcanza una síntesis del ser de estos países. La narradora actúa como la conciencia que filtra la realidad inmaterial del ser de Hispanoamérica. El "yo" que habla y cuenta su experiencia es real en la locución y crea un mundo de ficción que refleja, a través de la narración, la realidad del mundo en que se escribe. El personaje central, como el pícaro, recorre y unifica distintos ambientes sociales y modos de vida que enlazan la tradición con el mundo actual donde pulula una mezcla de razas, clases sociales y niveles económicos y culturales diversos.

El autor puede cambiar el punto de vista o la perspectiva desde la que contar o narrar los hechos que constituyen el mundo de la novela, aunque “también este mundo se crea a sí mismo a través de él, lo transforma en sí mismo, le obliga a entrar en el juego de las transformaciones, para manifestarse mediante él"' (Kayser, 1961, pág. 468).

La materia de las novelas hispanoamericanas está a la vista de todos, y esperando que los autores la tomen y la elaboren como materia narrativa: "hay una cierta materia que quiere decirse; y en un sentido no es el novelista quien hace la novela, es la novela la que se hace sola, y el novelista no es más que el instrumento de su venida al mundo, su partero" (Butor, 1960, pág. 273).

Muchas de estas novelas, sobre todo las de dictador, recurren al artificio de que no están escritas por el autor, sino por personajes más o menos próximos al círculo del tirano, o por este mismo.

En las novelas de F. Ayala Muertes de perro y El fondo del vaso, son dos espectadores de la tiranía, Pinedo y José Lino respectivamente, los que arti- 
culan los relatos con variadas formas: recopilaciones, confidencias, diarios, artículos de periódicos, etc.

En otras, como Yo, el Supremo de A. Roa Bastos, el relato aparece como la obra dictada por el tirano a su secretario Patiño, e intercala notas que se fingen escritas por el mismo Supremo.

En Oficio de Difuntos de A. Uslar Pietri, es el padre Solana el que cuenta la historia a partir de la muerte del dictador.

Otras veces es un narrador desconocido el que va contando y comentando los acontecimientos, a la vez que juzga los actos de la tiranía.

Todas estas variaciones permiten al lector acercarse al tema desde ángulos diversos que proporcionan enfoques próximos, medios o lejanos, para interpretar y juzgar libremente los acontecimientos y sus consecuencias.

En ocasiones varias voces cuentan los mismos hechos, lo que proporciona perspectivas que se entrecruzan y pueden ser sucesivas o simultáneas.

En Conversación en la Catedral de M. Vargas Llosa, aparecen sucesivamente el relato de Amelia y el de Ambrosio, a través de lo que este último va contando a Santiago. Son los mismos hechos pero no la misma perspectiva, y se manifiesta con variaciones simultáneas al utilizar un recurso en los diálogos consistente en entrecruzar intervenciones de distintos personajes y distintos tiempos en relación con temas comunes. Es lo que J. M. Oviedo denomina diálogos telescópicos, corte continuo y acotaciones dramáticas.

Estos recursos técnicos proporcionan variedad al resultado de la creación artística y al lector modos nuevos de contemplar lo ya conocido y participar activamente en la obra de arte.

La novedad de estos recursos está en relación con el tema: más actualizados son los de la novela del dictador o las de espíritu revolucionario, más tradicionales los relatos de tema indigenista.

En las novelas más recientes de temática revolucionaria se puede llegar a una aproximación a otros géneros como el ensayo o el género dramático.

El uso de tales recursos, unido a la intertextualidad, proporciona una intelectualización del relato, en el que los autores se permiten licencias artísticas, participando como personajes conscientes y críticos, y como actores interesados en el drama que viven sus respectivos países.

De los elementos de construcción o recursos comunes destacaremos cuatro fundamentales, que presentan variaciones en su tratamiento en los distintos tipos de novela, y son: los personajes, el espacio, el tiempo y la intertextualidad. 


\section{Los personajes}

En las novelas de dictador la figura omnipresente en el relato, aunque no necesariamente como protagonista, es la del tirano. De él emana el poder, una clase abusiva de poder, que ejerce directamente o a través de una figura interpuesta que actúa como "factotum".

Diversos estudios sobre esta clase de novelas permiten su identificación, al destacar una serie de rasgos de construcción que se reiteran en autores y obras.

A veces, el tirano aparece en todos los capítulos, como en Yo, el Supremo de A. Roa Bastos; otras sólo en algunos como en El Señor Presidente de M. A. Asturias. Su manera de actuar es, en todas, igual; su modo de ejercer el poder, también. Trata con la misma indiferencia un motivo sin importancia o la vida de un hombre, en cualquier caso es su voluntad la que siempre se impone. Todo lo que se le antoja se convierte en ley, pues las que pueden existir en su país no son obstáculo para hacer su voluntad. Nadie se pregunta si lo que ha ordenado el jefe está bien o mal, no se analiza, se ejecuta y con ello se procura hacer también lo que a cada uno le conviene. Todos buscan prebendas y dádivas, y procuran evitar castigos y condenas, que, cuando llegan, tampoco pueden eludir. Todo irradia del mismo foco, el tirano, que, por los nombres o apelativos que recibe, queda marcado desde el principio como centro de referencias y actitudes.

La conjunción de personaje, espacio y tiempo es determinante en este tipo de novela. Una vez desaparecida la circunstancia que une estos elementos esenciales de la narración, ésta se termina o desaparece, incluso cambia el tipo de narración, como se ve en ciertas novelas donde al sustituir alguno de los ingredientes habituales se desvirtúa su valor prototípico. Cuando El Supremísimo (Alonso, 1981) se desplaza a la selva pierde parte de sus características, aunque mantiene la visión irónica que es frecuente en los autores que tratan el tema. La parodia es tan burda que se acentúa la burla de una actuación, aunque trágica, inverosímil, al hacerse truculenta. El espacio, que no es el habitual, se apodera del personaje, impidiéndole actuar a su antojo. Las fuerzas de la naturaleza no le obedecen, son indiferentemente superiores.

En la misma novela se hace alusión a otro tirano, anterior al protagonista, y para el que ha terminado el tiempo de tiranía al ser desplazado fuera del país; su vida actual es la de un mendigo en Nueva Orleans. El tiempo y el espacio condicionan la actuación y fuera del contexto creado se acaba el personaje tirano. En ocasiones, el desplazamiento del dictador es voluntario, pero, también así, perderá su poder y para recuperarlo habrá de volver a la patria y pelear contra el que se lo ha arrebatado en su ausencia. Lo comprobamos en El re- 
curso del método de A. Carpentier. El personaje que habla en este relato, el tirano, se desplaza a Nueva York y a París, donde se comporta como un nuevo rico, más o menos caprichoso, pero no puede, como en su país, imponer su voluntad a nadie, ni siquiera a sus hijos. Cuando le anuncian que le han arrebatado el poder político, vuelve a su país y lucha de nuevo por él.

Acompaña al tirano un ejecutor de sus órdenes o "factotum", con el que habla cuando quiere mostrar sus pensamientos, que son interpretados casi sin enunciarlos. En Amelia (Mármol, 1984), es una mujer de la familia del tirano la que actúa como intérprete de la voluntad de Rosas.

A veces el "factotum" da su visión de la dictadura, lo que proporciona variedad al punto de vista. Las diferentes visiones condicionan el desarrollo del tema.

La figura del tirano lo preside todo, aunque no aparezca en muchos episodios, como en la obra de M.A. Asturias, El Señor Presidente, o en la de M. Vargas Llosa, Conversación en La Catedral, donde las innovaciones técnicas del discurso no impiden observar una sociedad en la que apenas aparece como personaje el tirano Odría (personaje real de Perú, que gobierna en 1948-56).

La novela puede ofrecer en este sentido - presencia o latencia del dictador- discursos diversos, variados.

No es un mundo normal el que engendra la dictadura, y para conseguir esta impresión la ficción deforma y distorsiona sus componentes, creando un mundo con personajes animalizados, muñequizados, movidos por sentimientos de temor o miedo, que les hacen actuar de manera grotesca. Esta visión deshumanizadora actúa sobre los personajes tanto si ejercen el poder como si lo padecen.

El sentimiento religioso, que se manifiesta muchas veces sedimentado en el lenguaje, resulta en estas situaciones una verdadera burla o parodia que aprovecha las circunstancias a gusto y acomodo del tirano, dándole una significación desviada para justificar actuaciones equívocas, fraudulentas. Los mismos tiranos son, con frecuencia, o como Luzbel, "aquel gran Luzbel sin fuego y sin eternidad como decía Solana" (Uslar Pietri, 1976, pág. 201), o como el Señor, o Supremo, en El Señor Presidente de M.A. Asturias o en Yo el Supremo de A. Roa Bastos. Esta condición sobrenatural también se da en personajes allegados a él, que se presentan como ángeles vengadores.

Los tiranos durante su mandato se asocian con todas las fuerzas sociales que les pueden hacer competencia y eliminan con su actitud los posibles brotes de oposición. Pero sus prebendas duran sólo lo que dura su poder,si éste se acaba, como se pone de manifiesto en las épocas de transición. 
Los autores suelen recurrir a escenas tópicas, donde se hace evidente la actitud del tirano, para mostrar la tiranía. Señalaremos:

a) Escenas que muestran las relaciones con la mujer y los hijos, origen, en muchos casos, de fatales consecuencias para el tirano..

b) Escenas con los miembros del gobierno, en las que se destaca la arbitrariedad del mandato tiránico. Es ejemplar en este sentido la escena de Bocanegra reunido con sus ministros en el cuarto de baño (Ayala, 1972). El lugar elegido pone de manifiesto la abyección de esta relación ignominiosa para los ministros que le rinden pleitesía y para él mismo, que lo consiente y lo estimula. El lugar comunica metonímicamente su degradación a la escena allí situada.

c) Los desfiles militares en los que el dictador se complace en mostrar su superioridad física. Escenas de este tipo aparecen en La fiesta del rey Acab de E. Lafourcade, o en Muertes de perro de F. Ayala.

d) Los negocios abusivos y sucios se presentan en relación con los montados por sus inmediatos seguidores con prostitutas y garitos; el tirano y sus adláteres, en su afán desmedido de lucro, permiten la degradación del hombre, si ello significa ganancia. Situaciones semejantes se ven en La fiesta del rey Acab, El Señor Presidente, o en Conversación en La Catedral.

e) Admiración frecuente por pesonajes de la historia que encarnan el ideal del mando supremo. Napoleón es uno de estos héroes. Hitler o César aparecen en otras ocasiones. En El Supremísimo, el tirano entabla una especie de competición con la historia de Napoleón al que sigue hasta el final; en Yo el Supremo de Roa Bastos se repite este afán imitativo. En El discurso del método, la erudición del primer mandatario le sugiere múltiples formas de alusiones a personajes históricos para usarlos en su propio beneficio.

f) Escenas en las que aparece el opositor al poder tiránico, que puede estar encarnado en personajes supervivientes de los antiguos linajes que ostentaban el poder feudal, estudiantes movidos por idealismos utópicos, los propios compañeros de mando que en un momento de debilidad del dictador se apoderan del aparato del poder en favor suyo, o los militares que se alzan en armas contra el tirano para imponer otra dictadura militar.

En algunos autores se observa el interés por analizar el proceso que va desde la oposición al tirano y las ansias libertarias de la juventud, al deseo de mandar sobre los demás. Así ocurre con el "estudiante" de El discurso del método, que sigue un proceso desde la revuelta juvenil a la participación en el régimen.

Como elementos ambientales se reiteran los actos públicos y solemnes en instituciones artísticas y académicas, donde los integrantes parecen rivalizar en 
alabanzas al tirano; la relación en tabernas o sitios públicos con el pueblo, el cual se presenta amorfo, sin individualizar; situaciones límite para la crueldad innecesaria y gratuita del dictador que no reconoce más ley que su capricho, actitud que tiene poder de imitación en los que le rodean, lo que convierte el círculo del tirano en un círculo dantesco de opresión y crueldad. En Muertes de perro, Tadeo Requena mata en el W.C. presidencial un perro amaestrado que le ha traído Luisito Rosales para obsequiar a Bocanegra y parece desencadenar con ello la locura del ministro y su suicidio; en Amelia, se asiste a una ejecución sumaria de un vendedor ambulante sólo porque molesta a Rosas el alboroto que provoca la tropa contra él, al creerlo espía; en El Señor Presidente, éste manda azotar a un subordinado por no realizar las órdenes a su gusto, y cuando le comunican que ha muerto, el Presidente muestra una total indiferencia. Otras veces son las brutalidades rebuscadas con los presos las que muestran la crueldad arbitraria y hasta chusca del dictador.

A veces el tirano puede aparecer como personaje dominante de una república sin ser titularmente gobernante, pero con un poder omnímodo capaz de imponer al titular que le conviene para sus negocios y manejar a los jefes de gobierno como marionetas que actúan según su deseo. El ejemplo más claro lo constituyen las novelas de L. Spota Retablo hablado, donde se presenta, partiendo del momento de su muerte, a Eugenio Olid en su ascensión al poder económico que le permite convertirse en un "auténtico sátrapa de la vida política mexicana, amo y señor del país, en cuyas manos rapaces confluyen los destinos de la nación. La inexcusable presencia del dictador o del presidente autocrático (títeres u hombres de paja del todopoderoso Olid) no se hace esperar" (Calviño, 1985, pág. 125). En Palabras mayores, "viene a representar una especie de amplificación secuencial y angular de la obra anterior por cuanto el tema gira en torno del problema sucesorio a la Presidencia" (ibíd.).

El tirano pueblerino aparece en Pedro Páramo de J. Rulfo o en Siete lunas $y$ siete serpientes de D. Aguilera Malta, donde el protagonista se presenta dividido; por una parte el jefe político o cacique y por otra el jefe militar que se nombra a sí mismo coronel y se impone arbitrariamente al pueblo por la fuerza de las armas. Viene esto a confirmar la teoría de que el militarismo o caudillismo es el germen del tirano y de su dictadura (Morales Padrón, 1962).

En Gracias por el fuego de M. Benedetti, el personaje R. Boudiño cuenta su vida y la relación con su padre, tirano familiar y social, a través del periódico que dirige "... la historia moderna uruguaya resulta filtrada a tenor de la crónica familiar en la que Boudiño (el viejo) representa la crapulosidad de un sistema que actúa a costa y de espaldas al pueblo; su figura es la de un tiranuelo de vaudeville, sin escrúpulos ni miramiento alguno" (Calviño, 1985, pág. 155).

En La muerte de Artemio Cruz de C. Fuentes, también el personaje central 
se presenta como un tirano de su entorno familiar y social, que surge, como es frecuente, de una revolución previa y se erige en nuevo tirano, o por lo menos en la nueva oligarquía que favorece la tiranía.

En las novelas indigenistas, los personajes suelen ser colectivos; a veces destacan individuos pero siempre prototípicos del pueblo que representan.

En estos relatos se describe la vida monótona pero idílica de una comunidad, con su sistema de vida y de autogobierno. Participan todos en las asambleas (hombres, claro, las mujeres no cuentan), y en los bienes comunes. Destacan las relaciones familiares y afectivas, la naturalidad espontánea de estas relaciones, la ignorancia del sistema de vida de los blancos y la repercusión de las leyes de éstos en las comunidades.

Se analizan también los modos de trabajar la tierra, de cuidar los rebaños, que son los principales medios de subsitencia en las comunidades rurales y de montaña, o su trabajo en las minas, o en las plantaciones explotadas por los extranjeros.

En sus creencias permanecen ritos ancestrales mezclados con el cristianismo, creando un sincretismo religioso en el que destaca la creencia en la transformación de los hombres en animales, nahualismo, mito que con frecuencia utilizan los autores con sus protagonistas. Estos, generalmente analfabetos, se guían por los conocimientos que les proporcionan sus tradiciones, la observación de la naturaleza y de sus fenómenos cíclicos. Su vidas es más natural y menos sofisticada que la de los blancos, son más "ingenuos" en el sentido filosófico del término.

A los indios se les integra en el sistema de vida de los blancos, arrancándoles a la fuerza de sus comunidades para llevarlos al ejército o a los puestos de trabajo obligatorio. Se ponen en contacto con otros hombres y con ideas que les permiten la defensa de su sistema de vida como un bien cultural que se debe mantener.

Las mujeres aparecen en la comunidad sin voz y sin posibilidades de manifestación o de desplazamientos que les permitan un mayor conocimiento y de sus derechos. Siguen a sus hombres y viven para cuidar de ellos y de los hijos.

Todo esto se puede observar en obras como la de C. Alegría El mundo es ancho y ajeno, o Los perros hambrientos. En El indio de G. López Fuentes, la raza es la protagonista, sin nombres propios. Presentan el mismo sistema de vida, aunque se desarrolla en espacios muy distantes y diversos geográficamente.

Las diferencias entre indios y blancos se manifiesta en obras como Los rios profundos de J. María Arguedas, a través de un niño blanco educado por indios, 
que al integrarse en el colegio con otros muchachos siente el trauma de las diversas culturas.

Las obras de M. Scorza pertenecientes a la pentalogía La guerra silenciosa se desarrollan en los Andes centrales, y los protagonistas son los indios de la región, despojados de sus tierras por el latifundismo de corte feudal que pervive todavía, o por las compañías yankees que explotan la minería de la zona.

Cuando un personaje se destaca de la masa amorfa de los indios para su defensa es porque en él se sienten representados todos los indios, como ocurre en Garambo, el invisible, en quien renacen diversas tradiciones. Cuando desaparece surge Agapito Robles, que actuará como nuevo héroe en el Cantar de Agapito Robles, con resonancias épicas ya desde el título.

Son novelas que no representan la lucha individual sino colectiva de la raza aborigen de cualquier parte de Hispanoamérica. Así lo confirman las palabras de C. Alegría: "La intención de llevar al indio a la novela, pese a las obras que tenía ya publicadas, me hacía confrontar dos problemas difíciles. El primero: mostrar el espíritu indígena, lo que implicaba un tratamiento novelístico de personajes. El segundo, según el tema que me había propuesto: presentar a un pueblo entero sin que se debilitaran los personajes" (Alegría, 1968, pág. 11).

En Huasipungo de J. Icaza se repite el mismo protagonismo de los indios del Perú.

En estas obras el indio no tiene voz, se la da el narrador, que no suele ser nunca indio, sino un observador extraño que recoge los motivos tradicionales y actuales de la desesperada situación de la raza. Este narrador es omnisciente para dominar desde su conocimiento la situación que le permita presentar la vida del indio con una perspectiva global.

Los problemas planteados en cada comunidad son variados y se llega a las luchas legales como en Redoble por Rancas o en El mundo es ancho y ajeno, de M. Scorza y de C. Alegría respectivamente.

Los protagonistas de las novelas de ideas revolucionarias suelen ser grupos, y cuando se destaca algún personaje es cabecilla prototipo, un estudiante o intelectual movido por una ideología de origen europeo que encauza la difícil situación de los países hispanoamericanos para desembocar en un movimiento de masas. En las relaciones de grupo se crean situaciones confusas, llegando a extremos como no saber la razón por la que se lucha, o hacerlo entre grupos de la misma ideología que parecen no encontrar nada mejor en qué aparentar acción. La obra de O. Soriano No habrá más penas ni olvido narra el enfrentamiento a muerte entre diversos personajes del mismo partido peronista que luchan ferozmente entre sí, hasta que interviene el ejército para calmar los ánimos, tras una serie de 
muertes y torturas increíbles. Crueldad gratuita que parece explicar lo inexplicable de una situación caótica que engendra violencia. Los hechos se sitúan en Argentina durante el último gobierno de Juan Domingo Perón.

En este tipo de novela siempre aparecen como contrapersonajes las fuerzas de orden público, abusando de su autoridad con torturas que son el objeto de la narración y que ponen de manifiesto la arbitrariedad del poder. En ocasiones son fuerzas paramilitares o grupos honorarios los que actúan impunemente amparados por la policía oficial.

Los personajes analizan interiormente sentimientos, recuerdos, preparación y esperanzas que suscita la acción, y las consecuencias que puede traer.

También es frecuente la observación, desde fuera, de la situación del país. Desde el destierro o el alejamiento temporal se ve con añoranza la lucha interior y el planteamiento de acciones que modifiquen la vida de todos. A veces estas reflexiones se hacen transcendentes al interrogarse los personajes sobre el ser de su patria, de su raza, o de sus hombres, analizado desde la historia que desemboca en el ser actual. Así ocurre en La región más transparente de C. Fuentes, o en Los convidados de piedra de J. Edwards, muy distintas en su realización, pero con el deseo común de analizar la situación y el ser de sus respectivos países en el momento actual: México y Chile.

En otras novelas revolucionarias es frecuente la presencia de un personaje itinerante que aparece y desaparece, enlazando y preparando acciones revolucionarias en distintos puntos de la nación, que alcanzan repercusión general. Los ojos de los enterrados de M.A. Asturias funde los temas de la tiranía y la explotación de las compañías bananeras y en la meditación final de uno de los personajes se analiza la lucha contra las dos: "La Dictadora y la Frutera caían al mismo tiempo y ya podían cerrar los ojos los enterrados que esperaban el día de la justicia...".

La figura revolucionaria del opositor se presenta con rasgos semejantes y denominaciones genéricas como "el estudiante", etc.

Las novelas unen personajes y actitudes que se completan, se relacionan y se reiteran en el panorama de los países hispanoamericanos, de los que se novela una realidad continuada en el tiempo, como se pone de manifiesto en Vista del amanecer en el trópico de G. Cabrera Infante.

\section{Espacio}

El espacio geográfico de los distintos países hispanoamericanos suele ser el marco genérico de cualquiera de los tipos de relatos tratados. 
Los espacios de la novela de dictador son distintos en los diversos autores, pero mantienen unas características comunes que permiten unificarlos en el sentido que tienen respecto al tema.

Todos los relatos de dictador se presentan en países reales o imaginarios de Hispanoamérica, recreada como un mosaico de espacios menores que al unirlos articulan el espacio genérico.

En la articulación de los micro-espacios predominan los urbanos y dentro de ellos el palacio presidencial, en la capital de la nación. En alguna obra se proporcionan espacios rurales correspondientes a los episodios del pasado, anteriores a la consecución del poder, o en la lucha por él.

Los micro-espacios concretos de cada novela no suelen precisarse, sin embargo, en ciudades identificables por indicios de realidad. La ambigüedad ambiental parece ser propia de la mayoría de estos relatos, que pretenden con ello una generalización.

En el círculo del poder tiránico se destacan diversos espacios menores y se crean una serie de cuadros yuxtapuestos que logran un fragmentarismo de piezas diseminadas que después encajarán en el rompecabezas que el lector recompondrá si quiere articular el mundo del tirano y de la tiranía.

Los espacios seleccionados están en función de los distintos aspectos sociales y de los valores que se quieren analizar: clases sociales, estamentos, grupos de poder (económico, religioso, militar, cultural), relaciones familiares, ambientes marginados, etc.

R. Gullón, al analizar el espacio en Tirano Banderas, señala la especialización intensa y añade: "Se ha dicho de Tirano Banderas que es una novela cubista y en el texto se hallan referencias directas al modo cubista de contemplar la realidad. Cubismo en este contexto, no sólo quiere decir fragmentación de la realidad, sino función representativa (metonimia, diría Jakobson) en cada uno de los fragmentos; el espectador - o lector - tiene que decodificarlos y reconstruir mentalmente la totalidad" (Gullón, 1980, pág. 58).

Lo mismo se puede aplicar a casi todas las novelas de dictador que utilizan el espacio fragmentado con un valor metonímico que comunica su sentido a la escena en él desarrollada y más aún a la tiranía en general. Una recepción en palacio, donde rinden culto al tirano los invitados selccionados para que lo hagan, significa el abigarramiento y la degradación de estos personajes de variada procedencia pero con el deseo común de figurar cerca del poder para conseguir sus ambiciones y medro personal por encima de la propia dignidad. Aparecen escenas de este tipo en La fiesta del rey Acab, en Amalia, en Muertes de perro o en El otoño del patriarca, etc. 
Los espacios de palacio, senado, Universidad, iglesia, donde se dan escenas en que interviene como protagonista el tirano, muestran la alucinante y obsesiva omnipresencia del poder tiránico en todos los puntos clave de la vida de un país dominado por la mirada de un individuo que se enfoca y proyecta sobre todo.

Las personas que no desean participar de la tiranía han de alejarse de los espacios controlados por la mirada del tirano o de sus colaboradores, donde sólo algunos inocentes o locos pueden actuar impunemente: el cura de Santa Rosa y el hijo de Luisito Rosales en Muertes de perro, o Bendición Alvarado en El otoño del patriarca; pero no siempre, como se ve en Señor Presidente.

Estos espacios de la tiranía son con frecuencia intertextuales, lo que no resta originalidad a la visión que del tema consigue cada autor.

Estas novelas, como todas, "modelizan un objeto infinito (la realidad) a través de los medios de un texto finito, la obra de arte sustituye con su espacio no una parte de la vida representada, sino la vida en su totalidad. Cada texto aislado modeliza simultáneamente un objeto particular y un objeto universal" (Lotman, 1982, pág. 263), y el conjunto de las obras que tratan un tema del que cada una constituye una visión particular, reiteran, sin embargo, elementos comunes que se hacen imprescindibles en el reflejo de una realidad que pasa a ser modelo universal. La visión se repite una y otra vez sobre el tiempo que va entre conseguir el poder y perderlo, generalmente a la vez que se pierde la vida. El novelista presenta el espacio vital desde el comienzo o desde el desenlace, lo que no tiene demasiada importancia, porque en cualquiera de los casos lo que intenta es poner de manifiesto que el poder tiránico tiene en sí mismo el principio del fin y éste llega como consecuencia lógica con el paso del tiempo.

El espacio de las acciones del tirano es aquel en el que destacan las características del despotismo, por eso es parte del desarrollo sintáctico del tema y queda condicionado por él, a través de la visión de los personajes, del narrador o del autor.

Para F. Aínsa "el paisaje ha ido dejando de ser el transfondo sólido de la novelística del mundo de cada día, para pasar a ser el complemento necesario de una acción significada en un sentido particular" (Aínsa, 1976).

Esta tesis se verifica en las novelas del dictador, cuya articulación de espacios en un sistema coherente crea un mundo alucinante que se debate entre dos extremos que se oponen, cielo e infierno, según la mirada que ilumina la escena y actúa de coordinadora de esa multiplicidad de espacios. Es la mirada, creo, lo que permite "atravesar las distancias" (Poulet, 1964) que existen entre los diversos espacios del sistema. 
Según sea la mirada, así serán los límites que imponga a los espacios en que han de moverse los actantes. La mirada del dictador limita el mundo de la dictadura.

Algunos críticos consideran este tipo de relato como novela de espacio, a pesar del relieve del personaje que las preside, porque lo más importante de ellas es el mundo en que vive y del que es reflejo.

Poco importa el lugar concreto que se da, porque la configuración social y espacial que articulan los episodios son manifestación de la dictadura estén donde estén. Su espacio tiene que ver con el infierno dantesco del que se podría decir que es el antecedente de un cosmos que se basta a sí mismo.El dictador genera un mundo de ficción cuyos habitantes pululan en un infierno donde ejercen su pecado dominante, la ambición, que arrastra al hombre al dominio de los demás hombres.

Los micro-espacios recurrentes insisten en una isotopía semántica que asocia poder y dictadura con un entorno definido.

Se podría añadir lo que Bolnow aplica al hombre en general: "El hombre (dictador) despliega su espacio a partir del centro en que se encuentra, dentro del marco de un horizonte limitante y creador de unidad" (Bolnow, 1969, pág. 79).

En las novelas indigenistas y de explotación yankee, a veces estrechamente relacionadas, los espacios son rurales, o pequeños poblados donde los indios mantienen sus tradicionales modos de vida en contacto con la naturaleza. Tierra y animales, su fuente de vida, crean el espacio novelesco en el que se destaca la vida de pastoreo o la agricultura más elemental.

Cada vez más arrinconados en lugares alejados de la vida urbana y limitados a zonas de escaso rendimiento, tienen una economía de supervivencia, modélica para enfrentarse a la explotación de que son objeto y a las catástrofes de la naturaleza, como vemos en obras de M.A. Asturias o de de C. Alegría.

De cualquier modo, el espacio que ocupan es vivencial pues en él encuentran uno de los factores que se consideran necesarios para vivir "las formas de la convivencia humana" (Bolnow, 1969, pág. 227). Se sienten identificados con el medio que el espacio les proporciona, y siguiendo con el citado autor "el modo como el hombre se encuentra en ese lugar (se refiere al espacio vivencial) puede ser muy diferente, según que el hombre esté perdido en el azar de algún sitio o si se siente vinculado a este determinado lugar, estimándolo como adjudicado y propio. El hombre puede encontrarse en el espacio perdido o amparado, en conformidad con él o bien sintiéndose extraño".

Los indios se han adaptado a su medio vital, y esto se pone en evidencia cuando son expoliados de sus tierras por la avaricia de los hacendados o por las 
explotaciones bananeras o mineras. En ocasiones se articulan espacios diferenciados para los habitantes de la zona y para los extranjeros, de modo que se contraponen dos sistemas de vida diferentes correspondientes a culturas distintas. El espacio del explotador, siendo cómodo, desaparecerá cuando se acabe la explotación de la tierra o sus productos, o cuando éstos no sean rentables, y el de los explotados, miserable, mantiene sus tradiciones, y sobrevivirá porque sus habitantes están más adaptados al medio.

El espacio residual de los indios, donde se dan unas condiciones de vida muy precarias es mimético de su condición reducida al límite.

Los escenarios de la vida de los indios son, sin embargo, mucho más amplios que en las novelas del dictador. Los protagonistas, las reservas indias, si las podemos llamar así, se integran en la naturaleza, por eso su temática se desarrolla en comunidades que viven en la montaña, en las altiplanicies o en las orillas de un lago o un mar no dominado por el hombre blanco.

La diversidad del paisaje americano es tan rica y variada que no se puede pretender una interpretación única y asimilable de ese paisaje. Se va domesticando a medida que diversos autores de las distintas naciones lo utilizan en sus obras ayudando a significar a otros elementos de la narración. Con el tratamiento de los diversos paisajes se cumple una misión asimiladora que llegará a reducir las características comunes a ese paisaje.

Se produce poco a poco un ordenamiento de lo que en principio se presentaba como inabarcable y en cierto modo caótico, dominando al hombre, de modo que el escritor fascinado por el paisaje lo hacía protagonista.

En principio muchos autores describen ese paisaje que predomina sobre el hombre, pero después se articula con el tema de la narración y éste lo limita y lo condiciona, según vemos en las novelas indigenistas, donde se pone en relación semántica con el tema.

"La dialéctica hombre-contorno ha empezado a encontrar sus líneas adecuadas, integrando por la palabra los elementos abrumadores de una aparente desproporción. La novelística latinoamericana empieza a conocer lo que debe ser relevante en una descripción, abandonando los detalles pintorescos, diversificados, cuando no meramente naturalistas o enfatizados por un presunto panteismo" (Aínsa, 1976, pág. 326).

El pueblo indio está tan integrado en el paisaje que apenas se destacan héroes individuales o colectivos que defienden sus "raíces". Así aparece en relatos como Hombres de maiz de M.A. Asturias, o en Todas las sangres de J.M"a. Arguedas.

La visión del paisaje se hace a través de un observador que entrecruza los hombres y su medio vital; por eso es frecuente la mimetización del hombre y 
del espacio de la que parte una mitologización que se repite de escenario en escenario, aunque éste sea diverso en cuanto los países en que se sitúan las acciones como Perú, Ecuador, México, etc.

Las novelas de espíritu revolucionario presentan como las demás un macroespacio situado en el continente americano, pero se ubican más concretamente en el país del autor o en otros donde el proceso revolucionario se manifiesta más abiertamente, e incluso sus protagonistas salen del continente y hablan desde el exilio adonde les han conducido sus actividades revolucionarias o su oposición al régimen; los personajes siguen ejerciendo su actividad desde países europeos, Francia y España preferentemente, coordinando acciones nacionales o internacionales con características de terrorismo revolucionario. Lo vemos en el Libro de Manuel de J. Cortázar. Sus protagonistas son exiliados hispanoamericanos que viven en París y montan un secuestro, en favor de su causa, que tenga resonancias universales.

Los micro-espacios se sitúan en ciudades, pueblos o incluso núcleos urbanos pequeños, nacidos al calor de la miseria o de la industria, donde se ponen en práctica las huelgas revolucionarias o se canalizan los descontentos aprovechando la facilidad de propaganda a través de creencias tradicionales que permiten encubrir o proteger a los activistas encargados de concienciar a la población descontenta y explotada.

Otras veces son las sierras o parajes inhóspitos los que acogen a un tipo de revolucionario que organiza la oposición al régimen establecido con fuerzas paramilitares, y lo combaten en guerrillas intermitentes. Se caracterizan estos espacios por la dificultad de acceso y lo intrincado de los caminos para llegar a ellos. Son reductos inaccesibles que los protegen del gobierno perseguidor.

El espacio se hace solidario del camuflaje necesario para la acción y la propaganda. En Los ojos de los enterrados se funden los temas del tirano, del indio explotado y de la revolución contra ambos. Se utilizan en ella leyendas indias relacionadas con lugares míticos concretos, como subterráneos que permiten a los cabecillas eludir la persecución de la policía y del ejército.

De este modo los espacios se asocian al tema y cobran vida aquéllos relacionados con la tortura, con las reuniones secretas y con lugares unidos a tradiciones misteriosas en relación con creencias indias o cristianas.

En estas obras, los espacios ponen de manifiesto los desplazamientos de los exiliados, las diferencias de las clases sociales, la inseguridad de ciertos lugares ocupados por los perseguidos, o los utilizados como salas de tortura o cárceles, siempre en manos de los oponentes.

Nota: La bibliografía de este estudio se incluirá en su segunda entrega, en el próximo número de Anales de Literatura Española. 